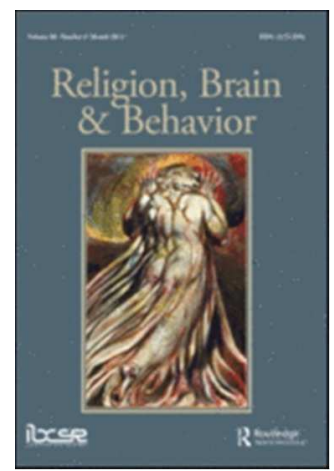

\title{
Recruiting and Pursuing Big Questions in the Scientific Study of Religion
}

\begin{tabular}{|r|l|}
\hline Journal: & Religion, Brain \& Behavior \\
\hline Manuscript ID & RRBB-2016-0076 \\
\hline Manuscript Type: & Target Article Commentary \\
\hline Keywords: & N/A, n/a, not applicable, none \\
\hline \multicolumn{2}{|l}{} \\
\end{tabular}

SCHOLARONE

Manuscripts 
Recruiting and Pursuing Big Questions in the Scientific Study of

$$
\text { Religion }
$$

Nicholas J. S. Gibson

John Templeton Foundation

\section{Author Note}

Nicholas J. S. Gibson, Human Sciences, John Templeton Foundation.

The opinions expressed in this article are those of the author and do not necessarily reflect the views of the John Templeton Foundation.

Correspondence concerning this article should be addressed to Nicholas J. S. Gibson, John Templeton Foundation, 300 West Conshohocken State Rd Suite 500, West Conshohocken, PA 19428, United States; email: ngibson@templeton.org. 
The editors of Religion, Brain \& Behavior deserve congratulations for their call for "Hilbert Problems" in the study of religion (Bulbulia, Wildman, Sosis, \& Spezio, 2015), as do those who responded to the call by contributing the thought-provoking essays in this special issue. While periodic pauses for reflection on progress-to-date and future priorities are a good indicator of the health of any thriving scholarly area (e.g., Barrett, 2007; Bonelli \& Koenig, 2013; Boyer \& Bergstrom, 2008; Emmons \& Paloutzian, 2003; Gorsuch, 1988; Paloutzian \& Park, 2013; Sedikides, 2010), I am not aware of any prior effort to assemble the Big Questions of multiple religion scholars in any systematic way. As I will argue, hearing from a diverse array of scholars is crucial if the scientific study of religion is to fulfil its potential.

\section{What Do Researchers Want to Do? (Or, By Their Funding Inquiries, Ye Shall Know Them)}

One response to recommendations to study new topics or use new methods is to ask whether scholars will actually follow such advice. Discussion sections of empirical papers are veritable graveyards of stillborn theories, abandoned hypotheses, and forgotten recommendations for things that "should be done [but not by me]." A special issue collecting recommendations and commentaries at least has the potential to provide a research agenda for the future that scholars might remember to refer back to; creating an open access location to revise and update the list of Big Questions over time might significantly multiply the chances of engaging the wider scholarly community. But the accessibility and salience of good ideas are not the only ingredients necessary to convince scholars to direct their attention toward particular research goals: motivation too is a factor. What topics do scientists studying religion actually want to study?

One way to answer this question is to investigate the kinds of projects for which researchers seek funding. Requests to the John Templeton Foundation (JTF) make an interesting case study, given that (a) JTF issues regular open calls for proposals (in contrast to most private funders), (b) a 
major focus of JTF's funding is support for the scientific study of religion, ${ }^{1}$ (c) JTF encourages interdisciplinary work (cf. Bromham, Dinnage, \& Hua, 2016), and (d) JTF explicitly uses the phrase "Big Questions" in describing the kind of work that it seeks to support (e.g., John Templeton Foundation, 2012). Of the 6,969 Online Funding Inquiries (OFIs; i.e., letters of intent) received by JTF between January 1, 2013 and September 1, 2016, 859 (12.3\%) could broadly be considered as requests for funding scientific study of religion. The median request size was $\$ 229,000$ and the mean request size was $\$ 611,994$.

A sense of the constructs, methods, and approaches of interest to those who applied can be approximated by analyzing counts of words or phrases within OFI titles, summaries, and project descriptions. ${ }^{2}$ I combined individual search terms into meaningful categories, many of which included themes recommended in the target articles. For example, I constructed the category “agency detection" (Barrett, 2000) from the following search terms (with the number of OFIs containing that term presented parenthetically): agency detect* (11), agent detect* (2), detect agen* (1), hadd (5), bypersensitive agen* (0), and byperactive agen* (5); only 15 of 859 OFIs included at least one of these search terms. The number of OFIs that referred to key topical and methodological categories can be found in Table 1. Two notes before proceeding: (1) given that not all instances of a particular search

${ }^{1}$ For example, of the 156 grants (worth $\$ 156.8$ million) that JTF approved in 2015, 18 (worth $\$ 20.8$ million) were for the scientific study of religion. Note that not all approved proposals originated via the OFI open submission process.

${ }^{2}$ One critique of this approach might be that it can only capture the conjunction between applicants' own interests and their perception of JTF's interests. The breadth of proposals submitted, however, suggests that the latter is either not always considered or else is sufficiently ambiguous (or open to motivated creative interpretation) that researchers' own interests are probably the dominant factor. 
term necessarily denote a focus on that concept, observed counts should probably be interpreted as maximum indications of interest within this set of grant proposals; (2) a consideration of what topics were actually approved for funding ${ }^{3}$ (and why) is beyond the scope of this paper, though I encourage the interested reader to explore the list of funded grants at www.templeton.org for more details.

[Table 1 about here]

\section{Topics}

The Big Questions raised by contributors can broadly be divided into three categories: (1) neglected topics with particular promise for broader theory development (e.g., exegesis, fertility, karma, or ritual killing); (2) older questions that bear reconsideration in the light of theoretical and methodological advances (e.g., relationships between religion and death anxiety, delusion, morality, or social capital); (3) application of theoretical lenses or approaches that have been relatively neglected within the study of religion (e.g., Bayesian approaches, computational modeling, network science, polyvagal theory, and predictive coding). Inspection of the counts in Table 1 suggests that relatively few scholars sought funds for such neglected topics or the application of theories from beyond the scientific study of religion. While applying is no guarantee of approval, it seems a shame that more scholars are not searching out undervalued ideas and developing them into project proposals. Failure to engage with broader theoretical developments is a long-standing problem, and may be one reason for the relative neglect of religion by the cognitive and behavioral sciences. Remedies may include increasing openness to theoretical articles on the part of religion journals,

${ }^{3}$ Of the 859 scientific study of religion OFIs, 112 were invited through to the full proposal stage and the remainder declined. At the full proposal stage, 44 (worth $\$ 40.1$ million) were approved for funding, 46 (worth $\$ 31.0$ million) were declined, 18 (worth $\$ 9.8$ million) were (at the time of writing) in preparation or under review, and 4 had been withdrawn. 


\section{Methods}

The target articles collectively make the case for using just about every tool available to researchers in the cognitive and behavioral sciences-semiotics, ethnography, interviews, field studies, survey panels, longitudinal designs, psychometrics, indirect (or "implicit") cognitive measures, socio-cognitive experiments, intervention studies, economic games, experimental linguistics, eye-tracking, psychophysiological measures, neuroscientific techniques, social network analysis, computational modeling and simulation, cross-cultural designs, cross-species comparisons, large-scale collaborative work, and database building and analysis are all mentioned_and for taking account of improved best practices in statistics and open science (Cumming, 2014; Gelman et al., 2013; Pashler \& Wagenmakers, 2012). May it become so: the scientific study of religion would be a significantly more robust field if researchers were indeed coordinating with each other to use such an eclectic array of methods to triangulate on what is true about the nature and functions of religion.

But despite these recommendations, and indeed despite the well-rehearsed problems in using self-report methods to study religion (Finke \& Bader, in press; Gibson, 2007; Gorsuch, 1984; Hill, 2013; Jong, 2013), the data in Table 1 suggest that questionnaire-based and qualitative methods of one kind or another continue to dominate the work that scholars of religion want to do.

Discouragingly few researchers request funds to use indirect measures of religious belief (even the physiological methods listed tend to be planned as outcome measures for investigations of the impact of [self-reported] religion on health), and few proposals even make reference to open science practices. Overcoming methodological provincialism may require more proactive efforts by field leaders, including, for example, convening methods symposia at specialty conferences, raising 
awareness of the breadth of research methods available (e.g., Lee, Bullivant, Farias, \& Lanman, 2016), organizing methodological summer schools, or facilitating collaborations with experts in the use of new methods or statistics.

\section{Whose Big Questions Are We Missing?}

\section{Representativeness}

Another approach to the Big Questions in this issue is to consider who is missing. In particular, I was struck by how few leaders within the psychology of religion, sociology of religion, or cognitive science of religion communities were represented. As a proxy measure of such individuals, I reviewed the names of those serving on the editorial or advisory boards of each of the major journals focusing on the scientific study of religion. Not one person listed (totals in parentheses) for Archive for the Psychology of Religion (29), International Journal for the Psychology of Religion (40), Journal for the Scientific Study of Religion (42), Journal of Cognition and Culture (27), Journal of Religion and Health (36), or Mental Health, Religion \& Culture (41) were among the published contributors. Of the remaining major journals, very few editorial board members were contributors: only 1 (Barrett) from Psychology of Religion and Spirituality (41), only 2 (Bulbulia and McKay) from Journal for the Cognitive Science of Religion (33), and only 4 (Barrett, Bulbulia, Norenzayan, and Schjoedt) from Religion, Brain \& Behavior (47). Clearly there are many other scholars with the potential to contribute Big Questions in the study of religion, so continuing efforts to solicit and collate such questions seems worthwhile.

\section{Interdisciplinarity}

Many contributors argued for more interdisciplinary research, and in particular recommended collaboration among scholars of religious studies, psychology, paleoanthropology, network science, experimental linguistics, and neuroscience. Certainly other disciplines could be added to this list. It is striking, however, that out of the 30 contributors, the primary institutional 
home of the majority was either in a psychology department (19) or a religious studies department

(6); only 4 were based in interdisciplinary institutes and only 1 in a sociology department. Even multidisciplinary work—let alone interdisciplinary work—will remain a challenge if we are not hearing from scholars in all of the relevant disciplines! The encouragement to break out of disciplinary silos is good, but institutional scaffolding or incentivizing of some kind may be necessary to turn this ideal into reality.

\section{International Diversity}

It is perhaps predictable that scholars from English-speaking nations were well represented: 21 of the 30 contributors had a primary institutional base in the United States, United Kingdom, New Zealand, or Canada. That the remaining contributors came from such (relatively) religiously diverse countries as Denmark, Germany, the Netherlands, and Turkey was promising. But we are still missing many voices, and it seems clear that the scientific study of religion would benefit from hearing the Big Questions of non-Western researchers. Increasing engagement and collaboration beyond the West will be complex and could take many years, but in the short-term, perhaps scholars of religion could learn from the recent efforts on maximizing diversity among the newly formed Society for the Study of Cultural Evolution.

\section{What Big Questions Went Unasked?}

The initial set of "Hilbert Problems" for the study of religion certainly represents a broad swathe of topics and approaches. Even so, many traditionally fertile areas for study were mentioned only in passing or not at all: what, for example, of the "dark side" of religion (Exline, Park, Smyth, \& Carey, 2011), of our understanding of typical developmental trajectories for religious cognition over the life span (Levenson, Aldwin, \& Igarashi, 2013; McFadden, 2013; Richert \& Granqvist, 2013), or of potential causal relationships between religious beliefs and health (as opposed to service 
attendance, e.g., Li, Stampfer, Williams, \& VanderWeele, 2016)? Another area in urgent need of research attention is the nature of affective processes within religious cognition. This empirical void has been highlighted on multiple occasions (Emmons \& Paloutzian, 2003; Gibson, 2008; Hill \& Hood, 1999; Watts \& Williams, 1988), but as yet with little response. In an effort to make the case in a new way, I offer three supplementary Big Questions for your consideration:

1. How do emotions directed toward supernatural agents differ from those directed toward other people? For example, studying how the cognitive processes involved in gratitude toward God (or indeed toward some transcendent non-agentic target, such as "the Universe") differ from those involved in gratitude toward other people might yield significant advances beyond our current rather emaciated understanding of how religious causal attribution works in practice (Hill \& Gibson, 2008; cf. Spilka, Shaver, \& Kirkpatrick, 1985; Weeks \& Lupfer, 2000). Investigation of the processes involved in other emotions toward supernatural agents, including love, awe, anger, guilt, shame, or fear, might similarly provide new insights with far-reaching implications, not just for our understanding of religious cognition but also for the broader psychology of emotion (Hill, 1999).

2. What are the cognitive processes involved when a person perceives being on the receiving end of the emotions or dispositions of a supernatural being? How, for example, does apprehension of God's forgiveness differ from receiving interpersonal forgiveness or even self-forgiveness? Addressing this question might provide insight into the cues that people look for in trying to perceive the mind of God (Gray \& Wegner, 2010; Wegner \& Gray, 2016), the processes involved in building, maintaining, or transforming particular religious attachment schemas (Granqvist \& Kirkpatrick, 2016), or the processes involved in religious conversion or spiritual transformation (Paloutzian, Murken, Streib, \& Rößler-Namini, 2013). 
3. What is the relationship between belief in an afterlife and hope and optimism? While afterlife beliefs have received some empirical attention (Bering, 2002; Hodge, 2011), such work has primarily focused on the naturalness of intuitions about surviving death as opposed to "living with heaven in mind". What characterizes the cognition and behavior of someone who is intrinsically motivated to "store up for [themselves] treasures in heaven" (Matthew 6:20)? For someone with a positive view of the afterlife, "eschatological hope" (Watts, 2002) might have interesting implications for judgment and decision-making.

\section{What Kinds of Questions Should Be Prioritized?}

I close with three general recommendations for future work; each ought to inform the other. First, as Barrett and Galen point out, the scientific study of religion is replete with conceptual fuzziness and weak research designs. Working through the implications for theory and method in the study of religion in the light of piecemeal (Barrett, 2007) and building-block approaches (Taves, 2009) seems crucial for progress; I suspect that doing so would reveal certain perennial questions to be ill-posed. Conducting this conceptual work in a way that integrates existing lines of inquiry with broader theoretical frameworks in the cognitive and behavioral sciences would be especially generative.

Second, I recommend significant empirical attention on questions that help to characterize the nature of major objects of inquiry. For example, what is "belief in God"? Is it one thing, many things, or in fact not a natural kind at all? Scholars of religion seem tempted to move quickly fromor bypass altogether- "what is it?" questions in a rush to get to "what does it do?" questions. Issues of structure, content, and mechanism are often skipped over in a rush to generate (for example) theories about the evolution of religion or functional accounts of religion's role in some other 
construct. Those are worthwhile endeavors, to be sure, but not before we have appropriately characterized the independent variable.

Finally, we must keep listening to each other's Big Questions and keep bringing new voices into the conversation. A recent similar effort to identify "grand challenges" within the field of cultural evolutionary studies identified 435 ideas from 236 contributors (Brewer \& MacDonald, 2015)! I am optimistic about where we are headed, but we have a long way to go. 


\section{References}

Barrett, J. L. (2000). Exploring the natural foundations of religion. Trends in Cognitive Sciences, 4, 29-34. doi: 10.1016/S1364-6613(99)01419-9

Barrett, J. L. (2007). Cognitive science of religion: What is it and why is it? Religion Compass, 1, 1-19. doi: 10.1111/j.1749-8171.2007.00042.x

Bering, J. (2002). Intuitive conceptions of dead agents' minds: The natural foundations of afterlife beliefs as phenomenological boundary. Journal of Cognition and Culture, 2, 263-308. doi: $10.1163 / 15685370260441008$

Bonelli, R. M., \& Koenig, H. G. (2013). Mental disorders, religion and spirituality 1990 to 2010: A systematic evidence-based review. Journal of Religion and Health, 52, 657-673. doi: 10.1007/s10943-013-9691-4

Boyer, P., \& Bergstrom, B. (2008). Evolutionary perspectives on religion. Annual Review of Anthropology, 37, 111-130. doi: 10.1146/annurev.anthro.37.081407.085201

Brewer, J., \& MacDonald, I. (2015). What are the grand challenges for cultural evolution? A research report for the Society for the Study of Cultural Evolution. https://www.academia.edu/18520184/What_Are_The_Grand_Challenges_For_Cultural_E volution

Bromham, L., Dinnage, R., \& Hua, X. (2016). Interdisciplinary research has consistently lower funding success. Nature, 534, 684-687. doi: 10.1038/nature18315

Bulbulia, J., Wildman, W. J., Sosis, R., \& Spezio, M. L. (2015). What are "The Hilbert Problems" in the study of religion? Religion, Brain \& Behavior, 5, 263-265. doi: 10.1080/2153599X.2015.1084470

Cumming, G. (2014). The new statistics: Why and how. Psychological Science, 25, 7-29. doi: $10.1177 / 0956797613504966$

Emmons, R. A., \& Paloutzian, R. F. (2003). The psychology of religion. Annual Review of Psychology, 54, 377-402. doi: 10.1146/annurev.psych.54.101601.145024

Exline, J. J., Park, C. L., Smyth, J. M., \& Carey, M. P. (2011). Anger toward God: Social-cognitive predictors, prevalence, and links with adjustment to bereavement and cancer. Journal of Personality and Social Psychology, 100, 129-148. doi: 10.1037/a0021716

Finke, R., \& Bader, C. D. (Eds.). (in press). Faithful measures: The art and science of measuring religion. New York: New York University Press.

Gelman, A., Carlin, J. B., Stern, H. S., Dunson, D. B., Vehtari, A., \& Rubin, D. B. (2013). Bayesian data analysis (3rd ed.). Boca Raton, FL: CRC Press.

Gibson, N. J. S. (2007). Measurement issues in God image research and practice. In G. L. Moriarty \& L. Hoffman (Eds.), God image handbook: Research, theory, and practice (pp. 227-248). New York: Routledge.

Gibson, N. J. S. (2008). Once more, with feelings: The importance of emotion for cognitive science of religion. In J. Bulbulia, R. Sosis, E. Harris, R. Genet, C. Genet \& K. Wyman (Eds.), The evolution of religion: Studies, theories, and critiques (pp. 271-277). Santa Margarita, CA: Collins Foundation Press.

Gorsuch, R. L. (1984). Measurement: The boon and bane of investigating religion. American Psychologist, 39, 228-236. doi: 10.1037/0003-066X.39.3.228

Gorsuch, R. L. (1988). Psychology of religion. Annual Review of Psychology, 39, 201-221. doi: 10.1146/annurev.ps.39.020188.001221 
Granqvist, P., \& Kirkpatrick, L. A. (2016). Attachment and religious representations and behavior. In J. Cassidy \& P. R. Shaver (Eds.), Handbook of attachment: Theory, research, and clinical applications (3rd ed., pp. 917-940). New York: Guilford Press.

Gray, K., \& Wegner, D. M. (2010). Blaming God for our pain: Human suffering and the divine mind. Personality and Social Psychology Review, 14(1), 7-16. doi: 10.1177/1088868309350299

Hill, P. C. (1999). Giving religion away: What the study of religion offers psychology. The International Journal for the Psychology of Religion, 9, 229-250. doi: 10.1207/s15327582ijpr0904_1

Hill, P. C. (2013). Measurement assessment and issues in the psychology of religion and spirituality. In R. F. Paloutzian \& C. L. Park (Eds.), Handbook of the Psychology of Religion and Spirituality (2nd ed., pp. 48-74). New York: Guilford Press.

Hill, P. C., \& Gibson, N. J. S. (2008). Whither the roots? Achieving conceptual depth in psychology of religion. Archive for the Psychology of Religion, 30, 19-35. doi: 10.1163/157361208X316944

Hill, P. C., \& Hood, R. W., Jr. (1999). Affect, religion, and unconscious processes. Journal of Personality, 67(6), 1015-1046. doi: 10.1111/1467-6494.00081

Hodge, K. M. (2011). On imagining the afterlife. Journal of Cognition and Culture, 11, 367-389. doi: 10.1163/156853711X591305

John Templeton Foundation. (2012). The first 25 years: John Templeton Foundation capabilities report. West Conshohocken, PA: Author.

Jong, J. (2013). Implicit measures in the experimental psychology of religion. In G. Dawes \& J. Maclaurin (Eds.), A new science of religion (pp. 65-78). New York: Routledge.

Lee, L., Bullivant, S., Farias, M., \& Lanman, J. (2016). Research methods for the scientific study of nonreligion. Retrieved from https://nsrn.net/2016/04/27/blog-series-research-methodsfor-the-scientific-study-of-nonreligion/

Levenson, M. R., Aldwin, C. M., \& Igarashi, H. (2013). Religious development from adolescence to middle adulthood. In R. F. Paloutzian \& C. L. Park (Eds.), Handbook of the psychology of religion and spirituality (2nd ed., pp. 183-197). New York: Guilford Press.

Li, S., Stampfer, M. J., Williams, D. R., \& VanderWeele, T. J. (2016). Association of religious service attendance with mortality among women. JAMA Internal Medicine, 176, 777-785. doi: 10.1001/jamainternmed.2016.1615

Luhrmann, T. M. (2004). Metakinesis: How God becomes intimate in contemporary U.S. Christianity. American Anthropologist, 106, 518-528. doi: 10.1525/aa.2004.106.3.518

Luhrmann, T. M. (2012). When God talks back: Understanding the American evangelical relationship with God. New York: Knopf.

McFadden, S. H. (2013). Old persons, old age, aging, and religion. In R. F. Paloutzian \& C. L. Park (Eds.), Handbook of the psychology of religion and spirituality (2nd ed., pp. 198-212). New York: Guilford Press.

Paloutzian, R. F., Murken, S., Streib, H., \& Rößler-Namini, S. (2013). Conversion, deconversion, and spiritual transformation. In R. F. Paloutzian \& C. L. Park (Eds.), Handbook of the psychology of religion and spirituality (3rd ed., pp. 399-421). New York: Guilford Press.

Paloutzian, R. F., \& Park, C. L. (2013). Recent progress and core issues in the science of the psychology of religion and spirituality. In R. F. Paloutzian \& C. L. Park (Eds.), Handbook of the psychology of religion and spirituality (2nd ed., pp. 3-22). New York: Guilford Press.

Pashler, H., \& Wagenmakers, E. J. (2012). Editors' introduction to the special section on replicability in psychological science: A crisis of confidence? Perspectives on Psychological Science, 7, 528-530. doi: $10.1177 / 1745691612465253$

Richert, R. A., \& Granqvist, P. (2013). Religious and spiritual development in childhood. In R. F. Paloutzian \& C. L. Park (Eds.), Handbook of the psychology of religion and spirituality (2nd ed., pp. 165-182). New York: Guilford Press. 
Sedikides, C. (2010). Why does religiosity persist? Personality and Social Psychology Review, 14, 3-6. doi: $10.1177 / 1088868309352323$

Spilka, B., Shaver, P. R., \& Kirkpatrick, L. A. (1985). A general attribution theory for the psychology of religion. Journal for the Scientific Study of Religion, 24, 1-20. doi: 10.2307/1386272

Taves, A. (2009). Religious experience reconsidered: A building-block approach to the study of religion and other special things. Princeton, NJ: Princeton University Press.

Watts, F. N. (2002). Theology and psychology. Aldershot, England: Ashgate.

Watts, F. N., \& Williams, J. M. G. (1988). The psychology of religious knowing. Cambridge, England: Cambridge University Press.

Weeks, M., \& Lupfer, M. B. (2000). Religious attributions and proximity of influence: An investigation of direct interventions and distal explanations. Journal for the Scientific Study of Religion, 39, 348-362. doi: 10.1111/0021-8294.00029

Wegner, D. M., \& Gray, K. (2016). The mind club. New York: Viking. 
Table 1

Number of Online Funding Inquiries Mentioning Key Methods or Topics

\section{Topics}

health (268), non-religion and secularity (190), evolutionary approaches (162), religious/spiritual development (160), well-being (157), prayer (115), ritual (95), religious/spiritual experience (79), god representations (67), cooperation (57), scripture (56), meditation (55), attribution (54), belief in gods (48), afterlife (41), attachment (41), service attendance (36), prosociality (31), conversion (28), religious/spiritual coping (26), theory of mind (26), anthropomorphism (24), agency detection (15), embodiment (12), liturgy (12), confession or repentance (10), death anxiety (8), signaling (8), exegesis (7), evangelism (5), fertility (5), karma (5), locus of control (5), pilgrimage (4), meaning system (2), glossolalia (1), sexual selection (0)

\section{Methods}

questionnaire (390), qualitative (319), neuroscience (189), interdisciplinary (182), physiological (128), longitudinal (76), genetic (96), cross-cultural (84), linguistic (33), priming (24), diary (16), computational modeling (10), economic games (10), big data (9), heart rate variability (9), eye-tracking (7), social network analysis (7), meta-analysis (6), semiotics (5), Bayesian statistics (3), pre-registration (3), systematic review (3)

Note. All totals are from a set of 859 funding requests to study religion. 